\title{
Outstanding Universal Value (OUV) as the foundation for conservation education betwixt local community in Malaysia
}

\begin{abstract}
Conservation practice in Malaysia has become more extensive for the past 15 years. It starts when the Malaysia Government was aiming to apply for the recognition of certain sites that has potential and substantial value to be awarded and listed under World Heritage Site from The United Nations Educational, Scientific and Cultural Organization (UNESCO) of The United Nation (UN). The government's intention starts with Melaka and Georgetown followed by Kinabalu Park, Gunung Mulu National Park and Lenggong Valley. These sites were chosen since it holds certain values of the local community and to government, such as historical value, authentic value, economic value, biodiversity value and socio-cultural value. Therefore, this paper will concentrate on conservation education by adapting Outstanding Universal Value (OUV) constituted by UNESCO by reviewing papers and publications that focusing on OUV and Conservation Education. Case studies of 3 World Heritage Sites in Malaysia were chosen. Concluded that OUV is applicable to become the foundation of conservation education for local community in Malaysia by adapting the 10 OUV based on the authenticity and characteristic of Malaysia.
\end{abstract}

Keyword: Outstanding Universal Value (OUV); Conservation education; Historical; Authenticity; Economics \& biodiversity 